\title{
Environmental impact on faecal glucocorticoid metabolite concentrations in Grevy's zebra (Equus grevyi)
}

\author{
Kelly Yarnell ${ }^{1 *}(\mathbb{D})^{\S} \&$ Susan L. Walker ${ }^{2}(\mathbb{D})$ \\ 'School of Animal, Rural and Environmental Science, Nottingham Trent University, Southwell, \\ Nottingham, United Kingdom, NG25 OQF \\ ${ }^{2}$ North of England Zoological Society, Chester Zoo, Caughall Road, Upton-by-Chester, \\ United Kingdom, $\mathrm{CH} 21 \mathrm{LH}$ \\ Received 26 April 2017. To authors for revision 3 June 2017. Accepted 1 September 2017
}

\begin{abstract}
The non-invasive nature of faecal glucocorticoid metabolite (FGM) assessment means that sample collection is on an opportunistic basis and samples cannot always be collected immediately upon defection during field studies. Faeces that have been exposed to heat and moisture may not accurately reflect levels of FGM. Our study exposed male $(n=3)$ and female $(n=3)$ Grevy's zebra (Equus grevyi) faeces to six environmental conditions to simulate a range of weather and seasonal patterns (temperate climate, high heat, high heat and rainfall, temperate climate and rainfall, high heat/temperate climate and freeze/thaw) over a period of five days. FGMs were quantified using an enzyme linked immunoassay. Results showed that environmental conditions do impact upon FGM levels over time, particularly in conditions that include high heat; however, regardless of environmental exposure, metabolites remain similar to baseline levels for up to $8 \mathrm{~h}$. We recommend that the investigation of environmental factors on sample integrity should be carried out as a validatory step when planning studies involving FGM analysis in any species.
\end{abstract}

Key words: adrenal, glucocorticoids, faecal.

\section{INTRODUCTION}

The Grevy's zebra (Equus grevyi) is estimated to have declined by more than $50 \%$ over the past 18 years. This is due to reduction of water sources, habitat loss, disease and competition for resources. It is now listed as endangered, with the current total population estimated at 750 mature individuals (Moehlman, Rubenstein \& Kebede, 2013). Conservation actions are now in place for the species, including the development of a national conservation strategy in Kenya. In addition, several other conservation studies, focused on wild populations and including issues such as community conservation (Low, Sundaresan, Fischhoff \& Rubenstein, 2009), protection of habitat and species monitoring (Williams, 2002) are now also in place.

To support conservation efforts and to effectively mitigate against losses, there is a need to under-

*To whom correspondence should be addressed. E-mail: kelly.yarnell@ntu.ac.uk stand the factors that may be leading to the decline of this iconic species. Conservation physiology is one tool that can achieve this goal and it provides a mechanism to assess population health and how an animal perceives or is challenged by its environment (Wikelski \& Cooke, 2006). If homeostasis is threatened, then the biological response might include elevated concentrations of circulating adrenal steroids (Sapolsky, Romero \& Munck, 2000). Biomarkers, such as faecal hormone metabolite analysis, can assess physiological status or the response of an individual to short and long-term environmental challenges, and assess the impact of management interventions (Wikelski \& Cooke, 2006; Cooke et al., 2013; Madliger et al., 2016). Faecal glucocorticoid metabolite (FGM) analysis is a frequently used biomarker for health and stress in wild animals and it is now broadly accepted as an effective, non-invasive method of monitoring adrenal activity (Wasser et al, 2000; Mostl \& Palme, 2002; Sheriff et al., 2011; Watson et al., 2013). However, care must be taken when interpreting the results of FGM analysis. For example, a decline in adrenal steroids is often 
interpreted as being indicative of acclimation to stressors, or their absence. However, declines in adrenal steroids may also occur through intrinsic controls which prevent them from remaining elevated for prolonged periods even under ongoing stress (Smith \& Dobson, 2001). This issue was demonstrated in a study which assessed the profiles of both adrenal and gonad conjugates (a measure of biological cost) in the faeces of black rhinoceros (Diceros bicornis) and white rhinoceros Ceratotherium simum) (Linklater et al., 2010). Both adrenal and gonadal profiles were temporarily elevated after capture and during captivity for translocation (Linklater et al., 2010). Corticoid levels did then decline but instead of returning to pre-capture levels, they became supressed below pre-capture levels. As the rhinoceroses were still displaying behavioural signs of stress (aggression and flight response) and supressed gonad hormone levels, it was hypothesized that corticoid suppression was due to intrinsic control and not acclimation (Linklater et al., 2010). This study highlights the complex nature of assessing the physiology of wild animals and the importance of using robust and appropriate methods.

Adrenal activity has previously been monitored in free-ranging plains (Equus burchelli) and Grevy's zebras. In the latter, Franceschini et al. (2008) used FGM to demonstate an initial elevation in adrenal activity post-translocation and capture (at 3-6 weeks), but with concentrations returning to pre-capture concentrations following release 11-18 weeks later. In the plains zebra, Fourie (2012) demonstrated the important links between sex, group size and adrenal activity; with males in larger groups exhibiting higher FGM levels than males in small groups, and FGM concentrations in females not differing between bands of different sizes. Due to the nature of these studies, beyond time from defaecation, no attempt has been made to evaluate the potential effects of environmental factors on faecal hormone concentrations. However, for research where immediate sample collection is not possible or where collection takes place across seasons, there is a need to understand the potential environmental impacts on hormone concentrations.

If the integrity of samples over time and during exposure to various climatic variables is investigated, then guidelines can be developed on appropriate sample collection. A study by Washburn \& Millspaugh (2002) found that white-tailed deer (Odocoileus virginianus) faeces that had been exposed to rainfall had artificially inflated FGM levels. By contrast, jaguar (Panthera onca) faecal samples exposed to sunlight did not show a change in FGM concentrations (Mesa-Cruz et al., 2014). However, wet conditions altered metabolite levels after five days of exposure (Mesa-Cruz et al., 2014). Consequently, the authors suggested running sample transects every three to four days in both wet and dry seasons (Mesa-Cruz et al., 2014).

Whilst the impact of field conditions on sample integrity has been studied in feral horses (Equus caballus) (Linklater et al., 2000), there are no published protocols that account for the effects of enivironmental variables on FGM analysis in Grevy's zebra. Significantly, the natural habitat of the species has climatic variability that encompass both periods of moderate and high heat and rainfall.

Our study was carried out to inform the sampling protocol of a larger study which included long-term sampling of zebra faeces for FGM analysis. The impact of time, and six simulated environmental conditions upon glucocorticoid metabolite concentration in the faeces of both male and female Grevy's zebra were investigated. We hypothesized that exposure to heat and moisture would result in fluctuation of faecal metabolite levels.

\section{METHODS}

\section{Faecal sample collection}

Faecal samples were collected from three male and three female captive adult Grevy's zebras who are part of the European Endangered Species Breeding Programme at Chester Zoo, United Kingdom. Zebras were observed for $1 \mathrm{~h}$ in total and samples were collected immediately upon defaecation. At least two samples per individual were collected with $100 \mathrm{~g}$ of faecal matter retrieved each time faeces were produced. This was to ensure that enough faecal matter was available for the study from all individuals. Diet at the time of collection consisted of $1 \mathrm{~kg}$ zebra cubes (Nutrazu) and $5.7 \mathrm{~kg}$ grass hay per animal per day with ad libitum water. Faecal samples were stored in a cooler bag for transportation to the laboratory and arrived within $2 \mathrm{~h}$ of deposition.

\section{Simulated environmental conditions}

A modified version of the method used by Washburn \& Millspaugh (2002) was employed in our study. Immediately upon arrival at the laboratory, the faecal samples were pooled and 
homogenized in two groups (1, male zebras; 2, female zebras). A sub-sample of $\sim 10 \mathrm{~g}$ was taken from each group and frozen at $-20^{\circ} \mathrm{C}$ to provide our pre-environmental treatment baseline (time 0 ).

The remaining faeces in each of the two groups were separated into $\sim 250 \mathrm{~g}$ sub-samples and each sub-sample was randomly assigned to one of six environmental simulation treatments which were: 1) room temperature (samples kept at $15^{\circ} \mathrm{C}$ ), 2) high heat (samples kept in an oven at $36^{\circ} \mathrm{C}$ to simulate summer conditions), 3) rainfall/room temperature $(25 \mathrm{ml}$ of rainwater every other day and kept at $15^{\circ} \mathrm{C}$ ), 4) rainfall/high heat (25 $\mathrm{ml}$ of rainwater every other day and kept in an oven at $36^{\circ} \mathrm{C}$ ), 5) high heat/room temperature cycle (samples kept at high heat in an oven at $36^{\circ} \mathrm{C}$ for $12 \mathrm{~h}$ and then at room temperature at $15^{\circ} \mathrm{C}$ for $12 \mathrm{~h}$ over; simulating summer heat and nightime cooling) and 6) freeze/thaw cycle (samples frozen for $12 \mathrm{~h}$ at $-20^{\circ} \mathrm{C}$ and then placed in an oven at $36^{\circ} \mathrm{C}$ simulating winter cold and daytime warming).

\section{Sampling protocol}

For treatments $1-4$, a sub-sample of $10 \mathrm{~g}$ was removed from both the male and female groups at $2 \mathrm{~h}$ from the baseline sample and then at $4 \mathrm{~h}, 6 \mathrm{~h}$, $8 \mathrm{~h}, 12 \mathrm{~h}, 24 \mathrm{~h}, 36 \mathrm{~h}$ and $48 \mathrm{~h}$ intervals from baseline sample. For treatments 5 and 6 , a $10 \mathrm{~g}$ subsample was removed from both the male and female groups at $12 \mathrm{~h}$ post-baseline sample and then at $24 \mathrm{~h}, 36 \mathrm{~h}, 48 \mathrm{~h}$ and $60 \mathrm{~h}$. All sub-samples were placed into plastic sample bags and labelled according to their treatment, time removed and sex and frozen at $-20^{\circ} \mathrm{C}$ until analysis.

Rainwater was collected in the week leading up to the study and stored in a refrigerator until it was applied to the relevant samples. We introduced a total of $4 \mathrm{ml}$ of rainwater to treatment 3 and $5 \mathrm{ml}$ to treatment 4 split into four applications (every $12 \mathrm{~h}$ ) over the $72 \mathrm{~h}$ treatment period. Rainfall was calculated from mean daily rainfall at Kakamega weather station, Kenya, during August and February, respectively, when temperatures and rainfall would be comparable to our simulations (Kenya Meteorological Service, 2015). Rainwater was applied using a small watering can.

To account for moisture loss and to standardize the weight of faecal sub-samples, each subsample removed was weighed and then divided by the number of remaining sub-samples to be collected. Throughout the experiment, faecal samples in treatments 1, 2, 5 and 6 were kept in $13 \mathrm{~cm} \times 13 \mathrm{~cm}$ Petri dishes and samples in the rain- fall treatments 3 and 4 were kept in $15 \mathrm{~cm}$ diameter sieves to allow slow drainage of water.

Room and incubator temperatures were monitored every $5 \mathrm{~min}$ throughout the experiment using a Lascar data logger (Thermosense, U.K.). Mean room temperature throughout the experimental period was $14.9 \pm 2.1^{\circ} \mathrm{C}$, oven temperature was $36.2 \pm 0.75^{\circ} \mathrm{C}$ and freezer temperature was $-20 \pm$ $0.05^{\circ} \mathrm{C}$.

\section{Faecal glucocorticoid metabolite (FGM) assay and statistical analysis}

Hormones were extracted from faecal samples following thawing and manual homogenization using a wet-weight shaking extraction adapted from Walker, Waddell \& Goodrowe, (2002) and described by Wong et al. (2016). Faecal extracts were stored until analysis on a previously described corticosterone antibody (CJM006 supplied by Coralie Munro; UC Davis). The Enzymelinked immunosorbent assay (EIA) was validated for measuring corticosterone metabolites in Grevy's zebra faeces, through parallelism (male $R^{2}=0.96, F_{(1,7)}=197.09, P<0.001$; female $R^{2}=$ $\left.0.95, F_{(1,7)}=123.57, P<0.001\right)$. Additionally, there was no evidence of matrix interference, as addition of diluted faecal extract to the standards did not alter the amount expected (male $R^{2}=0.99, F_{(1,7)}=$ 577.22, $P<0.001$; female: $R^{2}=0.99, F_{(1,7)}=$ 2824.85, $P<0.001$ ).

Cross-reactivities for the assay are published elsewhere (Watson et al., 2013) and only data with intra-assay CoV of less than $10 \%$ and inter-assay CoV of less than $15 \%$ were accepted and used for statistical analysis.

All data were analysed using IBM, SPSS V23 statistical software and are presented as mean \pm S.D.

\section{RESULTS}

An independent $t$-test was used to investigate any significant difference in FGM levels between sexes for each treatment group. No significant difference between sex was observed in any of the treatment groups (room temperature $t_{(38)}=2.4, P=0.09$, high heat $t_{(38)}=1.7, P=0.09$, rainfall/room temp $t_{(42)}=$ 2.1, $P=0.06$, rainfall/high heat $t_{(42)}=1.9, P=0.06$, high heat/room temperature $t_{(22)}=1.7, P=0.09$, freeze thaw $\left.t_{(26)}=1.3, P=0.2\right)$, therefore a repeated measures ANOVA was used to compare pretreatment (time 0) with post-treatment samples (hours $>2$ to up to $60 \mathrm{~h}$ ).

Three of the treatments demonstrated a signifi- 
cant change in FGM concentrations over time. Firstly, during the high heat treatment, there was a significant increase in mean FGM metabolite concentrations compared to time $0(28.8 \pm 7.8 \mathrm{ng} / \mathrm{g})$ at $24 \mathrm{~h}$ post-defaecation $(44.2 \pm 3.7 \mathrm{ng} / \mathrm{g}$; Wilks Lambda $=0.52, F_{(3,1)}, P=0.02$, multivariate partial eta squared $=0.47$; ; FGM concentrations continued to rise to $68 \pm 2.0 \mathrm{ng} / \mathrm{g}$ at $48 \mathrm{~h}$ post-defaecation (Fig. 1). Similarly, during the high heat/ room temperature treatment, FGM concentrations increased. However, these increases were not significantly elevated above that of time $0(29.8 \pm$ 7.8) until $48 \mathrm{~h}$ post-defaecation sampling point (Wilks Lambda $=0.000, F_{(3,1)}, P=0.02$, multivariate partial eta squared $=0.10)$. Metabolite levels increased from $30 \pm 3.1 \mathrm{ng} / \mathrm{g}$ at the $12 \mathrm{~h}$ sample point to $58.6 \pm 4.1 \mathrm{ng} / \mathrm{g}$ at the $48 \mathrm{~h}$ sample point and continued to rise to $88.3 \pm 28.4 \mathrm{ng} / \mathrm{g}$ at the $60 \mathrm{~h}$ post-defaecation sampling point (Fig. 1). By contrast, the rain/high heat treatment FGM concentrations decreased compared to time $0(29.8 \pm$ $7.8 \mathrm{ng} / \mathrm{g}$ ) and were significantly lower at $12 \mathrm{~h}$ post-defaecation $(17.1 \pm 6.6 \mathrm{ng} / \mathrm{g})$ Wilks Lambda $=$ $0.003, F_{(3,1)}, P=0.001$, multivariate partial eta squared $=0.99$ ); FGM concentrations continued to fall to $\sim 60 \%$ of concentations at time 0 , reaching $10.8 \pm 1.2 \mathrm{ng} / \mathrm{g}$ at $36 \mathrm{~h}$ post-defaecation.

There was no significant effect of time on FGM levels for the rain/room temperature treatment (mean $18.2 \pm 5$.) ng/g; Wilks Lambda $=0.05, F_{(3,1)}$, $P=0.3$ ) or the freeze/thaw treatment (mean
$25.88 \pm 5.8 \mathrm{ng} / \mathrm{g}$; Wilks Lambda $=0.001, F_{(3,1)}, P=$ $0.1)$. Similarly, there was no significant effect of time on FGM for the room temperature treatment (Wilks Lambda $=0.09, F_{(3,1)}, P=0.12$ ). However, the direction of the trend in the change of FGM was similar to the high heat and high heat/room temperature treatments, with FGM increasing from the $24 \mathrm{~h}$ sampling point $(42.7 \pm 7.2 \mathrm{ng} / \mathrm{g})$ to a numerical maximum of $62.5 \pm 37.6 \mathrm{ng} / \mathrm{g}$ at the $48 \mathrm{~h}$ sampling point (Table 1).

\section{DISCUSSION}

Our results indicate an optimal window of less than $8 \mathrm{~h}$ for sampling Grevy's zebra faeces if adrenal activity is to be measured.

The simulated environmental treatments that included high heat had an impact upon FGM levels. Washburn \& Millspaugh (2002) suggested that biochemical processes, such as the cleavage of conjugate side groups from hormone metabolites or the release of faecal glucocorticoids from lipid micelles, may increase faecal glucocorticoid metabolite levels. This may also be the case in our study with both the consistant high heat and alternating high heat/room temperature treaments demonstating rising concentrations of FGM. The prescence of high heat may have provided a favourable growth environment for microbes, causing the increase in FGM.

Constant high heat produced a greater increase within a shorter period of time $(44.2 \mathrm{ng} / \mathrm{g}$ and

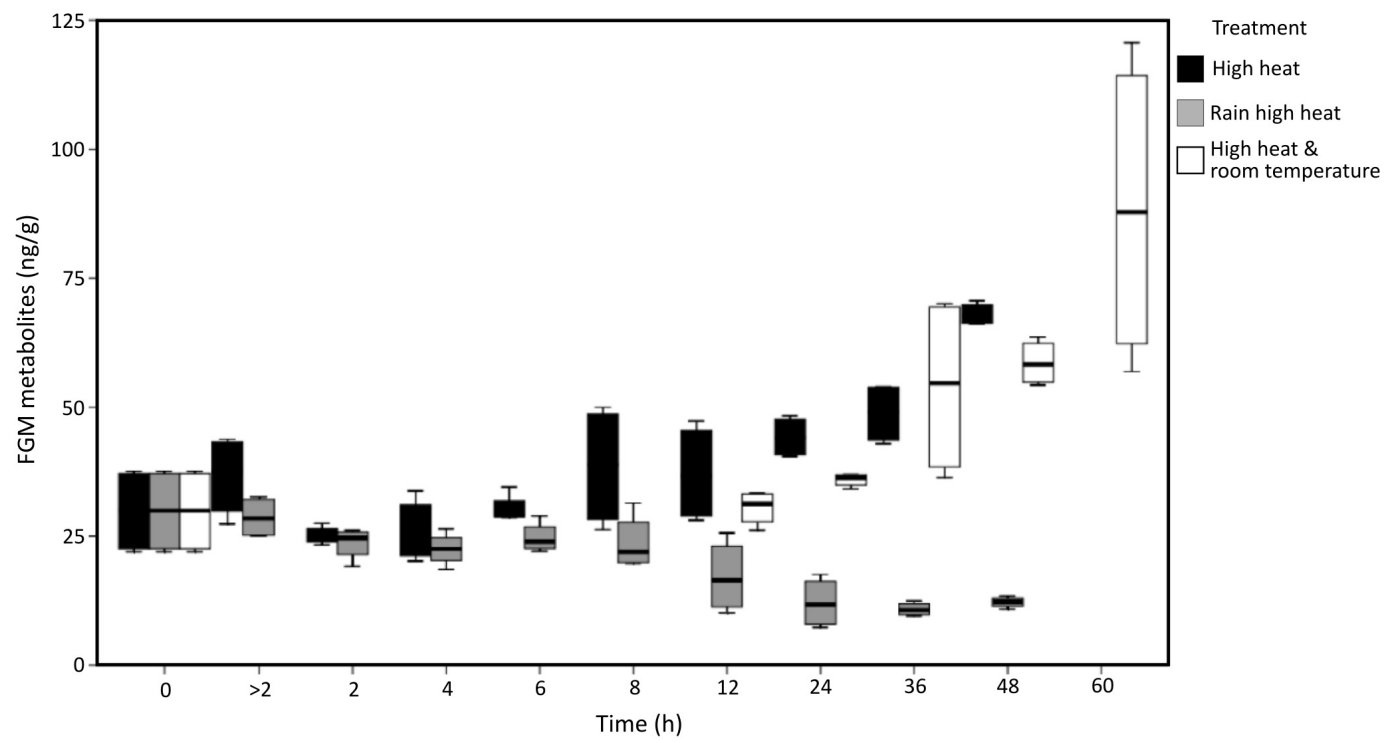

Fig. 1. Mean faecal metabolite concentration over time for the high heat, rain and high heat and high heat and room temperature treatments. 
Table 1. Mean ( \pm S.D.) faecal metabolite levels at each sampling time point for each of the treatments where no significant change was observed.

\begin{tabular}{|c|c|c|}
\hline Treatment & Time post-collection (h) & Mean ( \pm S.D.) FGM \\
\hline \multirow[t]{10}{*}{ Room temperature } & Baseline & $29.9(7.8)$ \\
\hline & $>2$ & $30.7(4.4)$ \\
\hline & 4 & $21.3(3.1)$ \\
\hline & 6 & $21.0(2.7)$ \\
\hline & 8 & $22.5(1.0)$ \\
\hline & 12 & $28.9(2.3)$ \\
\hline & 24 & $42.7(7.2)$ \\
\hline & 36 & $34.5(5.7)$ \\
\hline & 48 & $62.5(37.6)$ \\
\hline & 60 & $58.5(16.5)$ \\
\hline \multirow[t]{10}{*}{ Rain/room temperature } & Baseline & \\
\hline & $>2$ & $23.9(5.8)$ \\
\hline & 4 & $23.1(5.7)$ \\
\hline & 6 & $13.3(1.1)$ \\
\hline & 8 & $12.2(0.6)$ \\
\hline & 12 & $15.6(1.3)$ \\
\hline & 24 & $20.8(3.6)$ \\
\hline & 36 & $16.4(3.8)$ \\
\hline & 48 & $14.9(1.3)$ \\
\hline & 60 & $17.6(2.7)$ \\
\hline \multirow[t]{7}{*}{ Freeze/thaw } & Baseline & $29.8(8.4)$ \\
\hline & $>2$ & $22.8(6.7)$ \\
\hline & 12 & $21.1(1.99)$ \\
\hline & 24 & $25.2(3.6)$ \\
\hline & 36 & 31.7 (1.9) \\
\hline & 48 & $24.2(0.5)$ \\
\hline & 60 & $28.5(1.3)$ \\
\hline
\end{tabular}

$68.8 \mathrm{ng} / \mathrm{g}$ at the 24 and $48 \mathrm{~h}$ post-defaecation) than the intermittent high heat treatment (35.9 $\mathrm{ng} / \mathrm{g}$ and $58.6 \mathrm{ng} / \mathrm{g}$ at 24 and $48 \mathrm{~h}$ postdefaecation). This has implications for field-based sampling in similar climatic conditions. Studies taking place during seasons of hot weather, with limited rainfall, may result in the degredation of samples over a shorter period of time. In the current study, the room temperature treatment, although not significant, also demonstrated an increasing trend in in FGM levels over time. Therefore, it is not unexpected that the combined high heat/room temperature showed a rise in FGM over time.

The simulated rain conditions were conducted at both room temperature and with heat. Given that both the heat and room temperature treatments showed an increase in FGM, it was unexpected to see no change, or a downward change, with the addition of rain. It is worth noting that the current study was carried out in a laboratory which removed some potential sources of variation found in the field (wind, sunlight, insect activity). Grevy's zebras usually produce faeces in the form of large droppings with a hard outer layer. The mixing of the faeces from individuals during our study may have removed some of the outer covering, which could offer some degree of protection from the elements in field conditions. Nevertheless, our work has shown that exposure to rainwater or heat, both found in field conditions, does impact upon metabolite levels. However, repeating the manipulations under field conditions may yield further information that could be used to refine the sampling methodology.

Freezing and thawing faecal samples had no impact on FGM levels and concentrations remained stable $(25.88 \pm 5.8 \mathrm{ng} / \mathrm{g})$ up until $60 \mathrm{~h}$ post-defaecation. This is to be expected as a part of the current recommended sampling protocol is 
to freeze samples until analysis. In this case, the $12 \mathrm{~h}$ at room temperature before samples were reintroduced into frozen storage did not impact upon FGM levels. Freezing conditions are not expected in the natural habitat of Grevy's zebra but may be applicable where samples are required for additional or multiple hormone analysis.

Based on the findings of our study, we suggest that any planned adrenal monitoring using faecal samples needs to consider the impact of climate on the integrity of the samples. In addition, we would encourage similar work together with assay validation for other species.

\section{AKNOWLEDGEMENTS}

This work was supported by Nottingham Trent University and Chester Zoo. Thanks to Rebecca Purcell for technical support in the laboratory.

\section{REFERENCES}

Cooke, S.J., Sack, L., Franklin, C.E., Farrell, A.P., Beardall, J. \& Wikelski, M. (2013). What is conservation physiology? Perspectives on an increasingly integrated and essential science. Conservation Physiology, 1, 1-23.

Fourie, C.E. (2012). Vigilance behaviour and its endocrine correlates in Plains zebra (Equus burchelli) living in a predator-free landscape. (Unpublished M.Sc. thesis). Pretoria, South Africa: University of Pretoria.

Franceschini, M.D., Rubenstein, D.I., Low, B. \& Romero, L.M. (2008). Fecal glucocorticoid metabolite analysis as an indicator of stress during translocation and acclimation in an endangered large mammal, the Grevy's zebra. Animal Conservation, 4, 263-269.

Kenya Meteorological Service (2015). Weather and crop review for northwestern counties. Nairobi, Kenya.

Linklater, W.L., Henderson, K.M., Cameron, E.Z., Stafford, K.J. \& Minot, E.O. (2000). The robustness of faecal steroid determination for pregnancy testing Kaimanawa feral mares under field conditions. New Zealand Veterinary Journal, 48(4), 93-98.

Linklater, W.L., MacDonald, E.A., Flamand, J.R.B. \& Czekala, N.M. (2010). Declining and low fecal corticoids are associated with distress, not acclimation to stress, during translocation of African rhinoceros. Animal Conservation, 13, 104-111.

Low, B., Sundaresan, S.R., Fischhoff, I.R. \& Rubenstein, D.I. (2009). Partnering with local communities to identify conservation priorities for endangered Grevy's zebra. Biological Conservation, 142(7), 1548-1555.

Madliger, C.L., Cooke, S.J., Crespi, E.J., Funk, J.L., Hultine, K.R. \& Hunt, K.E. (2016). Success stories and emerging themes in conservation physiology. Conservation Physiology, 4, 1-17.

Mesa-Cruz, J.B., Brown, J.L. \& Kelly, M.J. (2014). Effects of natural environmental conditions on faecal gluco- corticoid metabolite concentrations in jaguars (Panthera onca) in Belize. Conservation Physiology, 2, (1), 1-10.

Moehlman, P.D., Rubenstein, D.I. \& Kebede, F. (2013). Equus grevyi. The IUCN Red List of Threatened Species 2013: e.T7950A21070406.

Munro, C.J. \& Stabenfeldt, G.H. (1984). Development of a microtitre plate enzyme immunoassay for the determination of progesterone. Journal of Endocrinology, 101, 41-49.

Mostl, E. \& Palme, R. (2002). Hormones as indicators of stress. Domestic Animal Endocrinology, 23, 67- 74.

Sapolsky, R.M., Romero, L.M. \& Munck, A.U. (2000) How do glucocorticoids influence stress responses? Integrating permissive, suppressive, stimulatory and preparative actions. Endocrine review, 21, 55-89.

Smith, R.F. \& Dobson, H. (2001). Hormonal interactions within the hypothalamus and pituitary with respect to stress and reproduction in sheep. Domestic Animal Endocrinology, 23, 75-85.

Sheriff, M.J., Dantzer, B., Delehanty, B., Palme, R. \& Boonstra, R. (2011). Measuring stress in wildlife: techniques for quantifying glucocorticoids. Oecologia, 166, 869-887.

Walker, S.L., Waddell, W.T. \& Goodrowe, K.L. (2002). Reproductive endocrine patterns in captive female and male red wolves (Canis rufus) assessed by fecal and serum hormone analysis. Zoo Biology, 21(4), 321-335

Washburn, B.E. \& Millspaugh, J.J. (2002). Effects of simulated environmental conditions on glucocorticoid metabolite measurements in white tailed deer feces. General and Comparative Endocrinology, 127, 217-222.

Wasser, S.K., Hunt, K.E., Brown, J.L., Cooper, K., Crockett, C.M., Bechert, U., Millspaugh, J.J., Larson, S. \& Monfort, S.L. (2000). A generalized fecal glucocorticoid assay for use in a diverse array of nondomestic mammalian and avian species. General and Comparative Endocrinology, 120, 260-275.

Watson, R., Munro, C.J., Edwards, K.L., Norton, V., Brown, J.L. \& Walker, S.L. (2013). Development of a versatile enzyme immunoassay for non-invasive assessment of glucocorticoid metabolites in a diversity of taxonomic species. General and Comparative Endocrinology, 186, 16-24.

weathersa.co.za. (2016). Historical Rain Maps. [online] Available at: http://www.weathersa.co.za/climate/historical-rain-maps [last accessed 1 July 2015].

Wikelski, M. \& Cooke, S.J. (2006). Conservation physiology. Trends in Ecological Evolution, 21, 38-46.

Williams, S.D. (2002). Status and action plan for the Grevy's zebra (Equus grevyi). In P.D. Moehlman (Ed.), Equids: zebras, asses, and horses: status survey and conservation action plan. Gland, Switzerland IUCN/SSC Equid Specialist Group,

Wong, E.P., Yon, L., Purcell, R., Walker, S.L., Othman, N., Saaban, S. \& Campos-Arceiz, A. (2016). Concentrations of faecal glucocorticoid metabolites in Asian elephant's dung are stable for up to $8 \mathrm{~h}$ in a tropical environment. Conservation Physiology, 4(1), $1-7$. 